\title{
Does the Stage of the Business Cycle Affect the Inflation Rate?
}

\author{
JOHN A. TATOM
}

VIT of expansion and approaching high rates of resource employment, renewed fears of accelerating inflation have surfaced. One source of such concern is the widely held view that the rate of inflation is a cyclical phenomenon, falling during recessions and rising as the economy approaches a cyclical peak. According to this explanation, inflation is influenced by the degree of slack in markets for goods, services, and resources. When there are ample supplies of unused resources available, price pressures are presumed to diminish. Similarly, the inflation rate is believed to accelerate as high employment conditions arise. During such periods, resource availability becomes more limited and firms, competing for scarce resources to meet growing demand for their products, bid up resource prices and consequently product prices. ${ }^{1}$

Such an explanation has considerable appeal since it appears to be based upon standard supply-demand considerations, but the analysis is incomplete and its use for explaining inflation is limited. The explanation obscures the nature of the inflationary process, fostering confusion about the cause of inflation and, more important, confusion over appropriate Government policies.

An alternative view contends that inflation results from a sustained rate of growth in the money stock which exceeds the growth rate of the quantity of money demanded by the nation's wealth owners. While the focus of this view is on the economy's rate of monetary expansion, it leaves open the possibility that in the short run, slack, or its absence, can

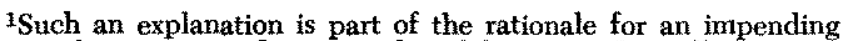
acceleration in inflation predicted by Irwin L. Kellner, Business Repon, Manufacturers Hanover Trust, Spring 1978. The view that slack, or the lack of it, influences the outlook for the inflation rate has also been expressed recently by Lindley H. Clark, Jr. "How Much Slack?", The Wall Street Joumal, May 2, 1978 and in "The Labor Market May Be Breeding Inflation," Business Week, July 31, 1978, pp. 93-94. Such analysis also plays a crucial role in the Council of Economic Advisers' recent discussion of the inflation problem. See Economic Report of the President, 1978, pp. 149-50, 168-72. exert an additional independent influence on the rate of inflation. The analysis below indicates that such an independent causal link between slack and the inflation rate is not supported by recent experience, once the rate of monetary expansion is taken into account. An apparent relationship between the rate of inflation and the extent of slack in resource and goods markets can easily arise, however. When monetary growth is procyclical, the timing of the impact of changes in monetary growth on the extent of capacity utilization and on the inflation rate can give rise to such observations.

For example, a recession can be caused by a slowing of the growth rate of the money stock. Such a slowdown in money growth, if sufficiently sharp and maintained, will reduce the growth rate of total spending for final goods and services, expectations of inflation, and the rate of inflation. As a consequence, increased slack (temporarily) and reduced inflation will both be observed, but each is solely the result of the pattern of money growth. There need be no independent causal relationship between economic slack and the inflation rate.

Similarly, an acceleration in monetary growth can cause a temporary reduction in slack in the economy while fueling the longer-term trend rate of growth of the money stock and, consequently, the inflation rate. Such a sequence of events would ensure that an acceleration in the rate of inflation, as well as tighter markets for resources, goods, and services, would be observed at about the same time, but again solely as a consequence of the pattern of money growth.

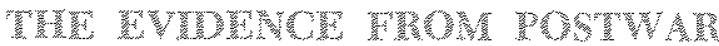 TCESSTONS}

Slack is not a well defined economic concept, but it refers to conditions in which existing resources are not utilized to the extent associated with "full employment." Such underutilization is typically represented by a higher unemployment rate or a lower 


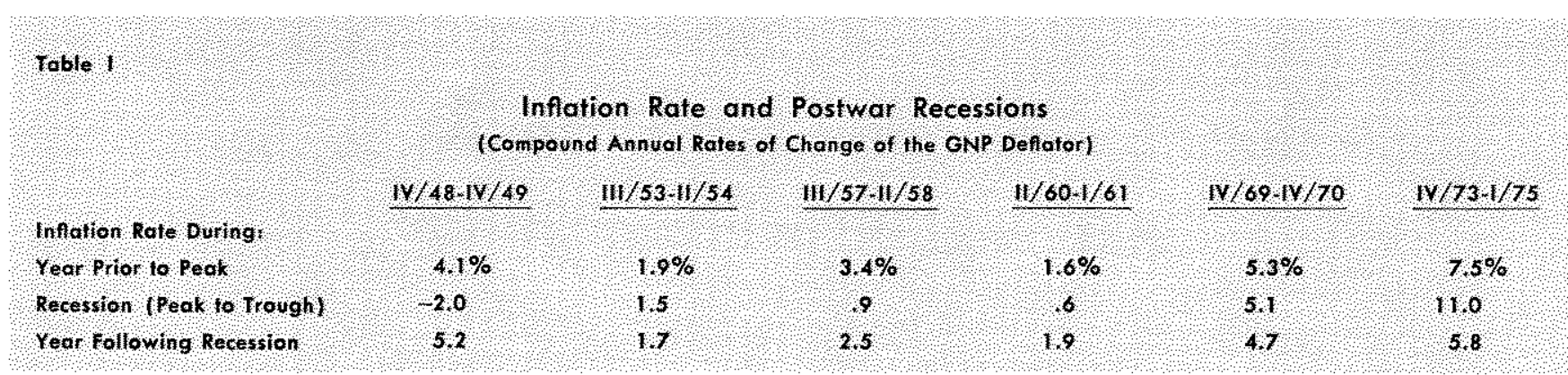

utilization rate of manufacturing plant and equipment than the rates achieved during economic booms. Even without a precise definition, however, most observers would agree that during a recession the economy has sufficient resources available at existing resource prices to produce goods and services at a faster rate than is observed. During the early periods of economic recovery following a recession, more slack would be present than during the peak period before the recession. Thus, some evidence on the relationship between the degree of economic slack and inflation can be obtained by looking at the inflation rate which existed before, during, and after the six postwar U.S. recessions. If inflation is a cyclical phenomenon, rising and falling with the pace of economic activity, then the inflation rate should be greatest during the period immediately prior to a cyclical peak, and lower during the recession and subsequent recovery period.

In fact, the evidence from the four postwar recessions prior to the 1970s appears to be fairly consistent with the cyclical view (Table I). In each case, inflation was not a significant problem during the recession, averaging no more than a 1.5 percent annual rate. In the first recession (1948-49), prices actually fell, on average. Also in each case, the rate of infiation was lower than in the year prior to the recession. A comparison of the inflation rate in the year following a recession with that prevailing prior to the recession yields mixed results. In two of the first four recessions, prices rose slower after the recession than they did before the recession, and in two cases they rose faster following the recession.

In contrast, the rate of inflation was relatively high during the two most recent recessions. Nonetheless, even these experiences appear to offer some evidence supporting the cyclical view. In the 1969-70 recession, the inflation rate slowed slightly during the recession and in each of the two cases, the inflation rate was lower in the year following the recession than it had been in the year preceding the recession. While the postwar evidence is not com- pelling, it does, in the majority of cases, appear to be consistent with the cyclical view of inflation.

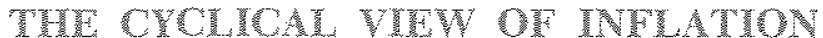

The cyclical view is embodied in what is referred to as the "Phillips Curve," which indicates a trade-off relationship between the rate of inflation and the unemployment rate such as that shown in Figure I. ${ }^{2}$ The existence of such a trade-off means that policymakers can only choose among the available combinations of unemployment and inflation in setting policies. In the cyclical context, it is clear from Figure I that the lower unemployment rate associated with a cyclical peak requires a higher inflation rate,

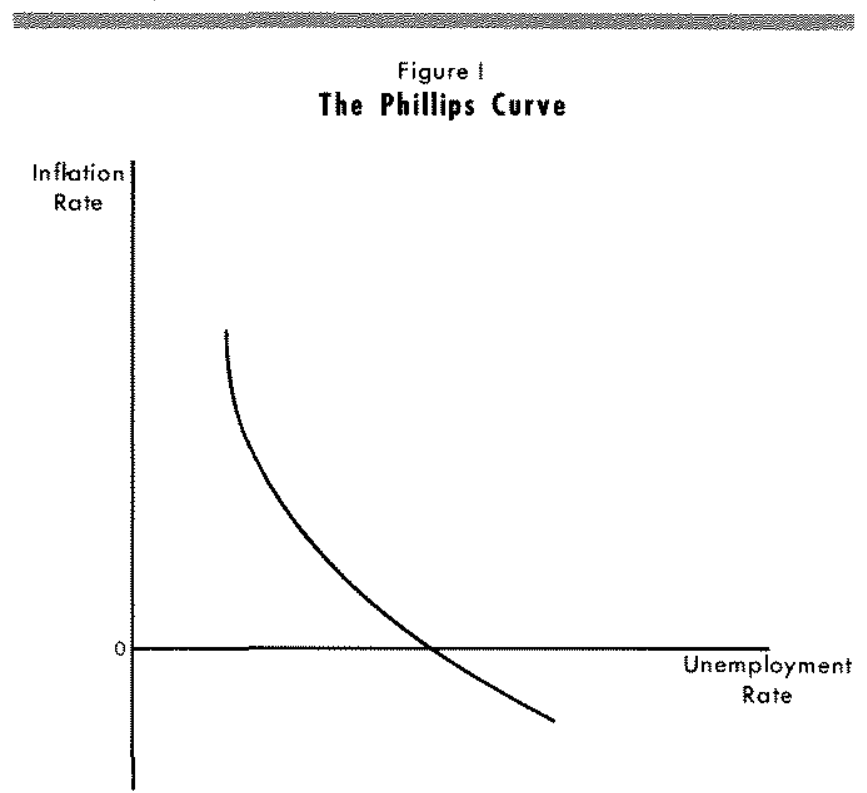

2See A. W. Phillips, "The Relation Between Unemployment and the Rate of Change of Money Wage Rates in the United Kingdom, 1861-1957," Economica (November 1958), pp. 283-99, and Richard G.' Lipsey, "The Relation Between Unemployment and the Rate of Change of Money Wage Rates in the United Kingdom, 1862-1957: A Further Analysis," Economica (February 1960), pp. 1-31. The original analysis was stated in terms of a wage inflation-unemployment rate trade-off. This was quickly translated into a price inflation-unemployment rate trade-off by assuming that prices of goods and services are a constant mark-up over wage costs. 
while a lower inflation rate occurs only when the unemployment rate is higher, such as during a recession.

During the decade of the $1960 \mathrm{~s}$, such a trade-off was believed by many observers to be stable and to arise from the application of supply and demand analysis to the market for labor services. In the past decade, however, it has become increasingly uncertain that such a stable empirical relationship exists. Chart I shows the combinations of the annual inflation rate and unemployment rate for the United States from 1954 to 1977 . From 1954 to 1969 the hypothesized relationship appears to exist and to be fairly stable. The gyrations of inflation and unemployment in the seventies, however, eliminate confidence in the existence and stability of the Phillips Curve.

Moreover, a considerable literature has developed since the late $1960 \mathrm{~s}$ on the factors which influence the Phillips Curve, and views concerning it have changed markedly. ${ }^{3}$ The most notable developments concern the "natural rate hypothesis" and the "expectations-adjusted Phillips Curve." The natural rate hypothesis indicates that in the long run the Phillips Curve is vertical at a "natural" unemployment rate where unemployment is associated with only frictional and structural characteristics of labor markets. The expectations adjustment allows the short-run Phillips Curve to shift in response to changing expectations concerning the inflation rate. ${ }^{4}$

These two developments are represented in Figure II where the long-run Phillips Curve is indicated at the natural unemployment rate $\mathrm{U}_{\mathrm{n}}$, and the short-run Phillips Curve is drawn as before, but its position can shift in response to changes in the expected rate of inflation, $\pi^{*}$. Unlike the earlier trade-off view, the dynamics of inflation and unemployment adjustment

${ }^{3}$ See Thomas M. Humphrey, "Some Recent Developments in Phillips Curve Analysis," Federal Reserve Bank of Richmond Economic Review (January/February 1978), pp. 15-23, for a discussion of the evolution and according to some theorists, the denise of the Phillips Curve analysis. Also, see Anthony M. Santomero and Johm J. Seater, "The Inflation- Unemployment Trade-off; A Critique of the Literature," Joumal of Economic Literature (June 1978), pp. 499-544. One of the original empirical studies of these developments is Leonall $C$ Andersen and Keith M. Carlson "An Econometric Analysis of the Relation of Monetary Variables to the Behavior of Prices and Unemploynent," The Econometrics of Price Determination, Proceedings of a Conference Sponsored by Board of Govemors of the Federal Reserve System and Social Science Research Council, Washington, D.C., October 30-31, 1970, pp. 166-83,

tThese developments, as well as the importance of two different views of the Phillips Curve for policy analysis, are discussed in the accompanying Review article by Keith M. Carlson, "Inflation, Unemployment, and Money: Comparing the Evidence from Two Simple Models."

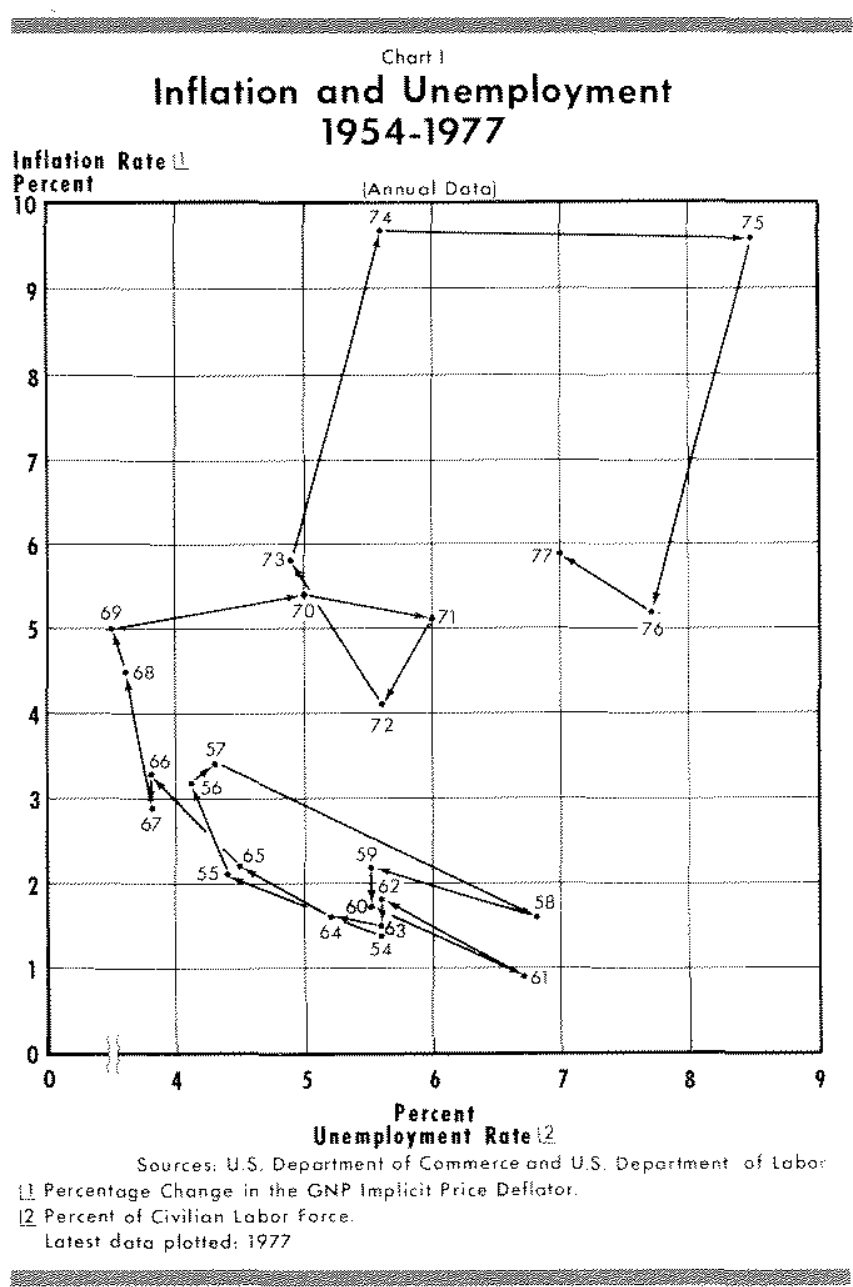

introduced by these hypotheses does not require that a unique relationship between slack and the inflation rate exists. While an inverse relationship exists for movement along a short-run Phillips Curve, shifts in the curve can lead to the observation of both rising inflation and rising unemployment (such as from 1973 to 1974), or both could fall (such as from 1975 to 1976).

For example, suppose the economy is at point A in Figure II and the monetary authorities increase the rate of money stock growth in an attempt to reduce unemployment. According to the old Phillips Curve view, output demand and employment demand would expand, reducing unemployment. Moreover, as employers bid up wages in their attempt to expand employment, the inflation rate would rise to $\pi_{1}$. The economy would move to point $B$. The change introduced by the newer view is that such a policy would lead to revised expectations of inflation, shifting the short-run curve upward. The natural rate 


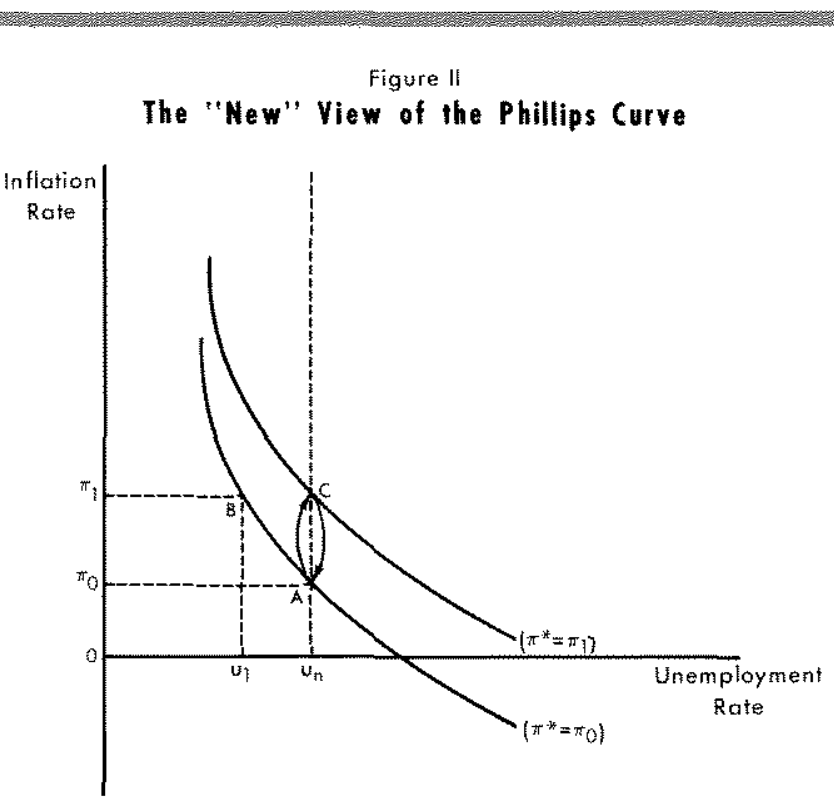

would tend to be restored so that actual inflation would equal the anticipated rate at point $C$. The movement from point $\mathrm{A}$ to $\mathrm{C}$ could follow the path shown by the upward arrow, where initially inflation and slack would move in opposite directions, and later in the same direction. Similarly, a policy action to lower inflation to $\pi_{0}$ could lead to the reverse path indicated by the downward arrow from $\mathrm{C}$ to $\mathrm{A}$.

Thus, even if there is a short-run Phillips Curve which exhibits an inverse relationship between the inflation rate and the unemployment rate, there is little reason to expect that observed changes in the two measures will represent movements along the curve. Instead, expectational factors, according to the new Phillips Curve view, can give rise to both direct and inverse relationships between slack and the inflation rate. While the observations in Chart I may or may not be compatible with the new view of the Phillips Curve, such a view offers little support for the existence of a unique trade-off and even less support for its relevance, in the short run. In the long run, it denies the existence of the inverse relationship.

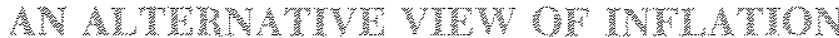

One of the oldest and most tested postulates of economic theory is that inflation is a monetary phenomenon. A sustained change in the rate of growth of the stock of money inevitably causes a similar change in the inflation rate. When inflation is viewed in this context, the question addressed here must be restated.
While the extent of slack in the economy alone does not appear (Chart I) to account for the inflation rate, it may be that slack exerts some independent influence. Does the state of economic activity, as indicated by measures of "slack," influence the rate of inflation independently of the course of monetary growth? To examine this question, a standard formulation of the money-price link is developed. Then the question of the independent influence of slack on the inflation rate, given monetary growth, is addressed.

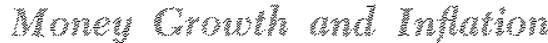

The linkage between the growth rate of money and inflation is usually thought to arise from a stable relationship between the stock of money (and its growth rate) and the dollar value of the nation's income or total spending on final goods and services (and its growth rate). An increase in the rate of growth of the money stock, according to this view, results in a proportionate rise in the growth rate of total spending. This growth in total spending can be divided into the rate of increase of the dollar prices of the nation's output (inflation) and the rate of growth of the volume of output. In the long run, the output-growth component of spending demand tends to be constant. ${ }^{5}$ Thus, a change in the growth rate of the money stock ultimately tends to be reflected fully in the rate of change in prices or the inflation rate.

As an empirical matter, the response of spending to a change in the growth rate of the money stock does not occur instantaneously but, instead, appears to be completed over a four-quarter period. More importantly, the initial spending response to a change in the growth rate of the money stock is primarily reflected in the real output growth component instead of in the inflation rate. The proportional impact of money stock growth on the inflation rate occurs only after a fairly long period of adjustment. ${ }^{6}$

The hypothesis that the rate of inflation depends upon the long-term rate of money growth has been formalized in an equation which relates the rate of inflation in a quarter directly to the rate of monetary

TThe rationale for this steady growth in output is that the growth of the nation's ability to produce output is determined by growth in the supplies of resources such as labor and capital and the growth rate of resource productivity and these growth rates tend to be fairly constant.

GOne study which provides a more detailed statement of the theory and evidence supporting these conclusions is Leonall C. Andersen and Keith M. Carlson, "A Monetarist Model for Economic Stabilization," this Review (April 1970), pp. 7-25. 


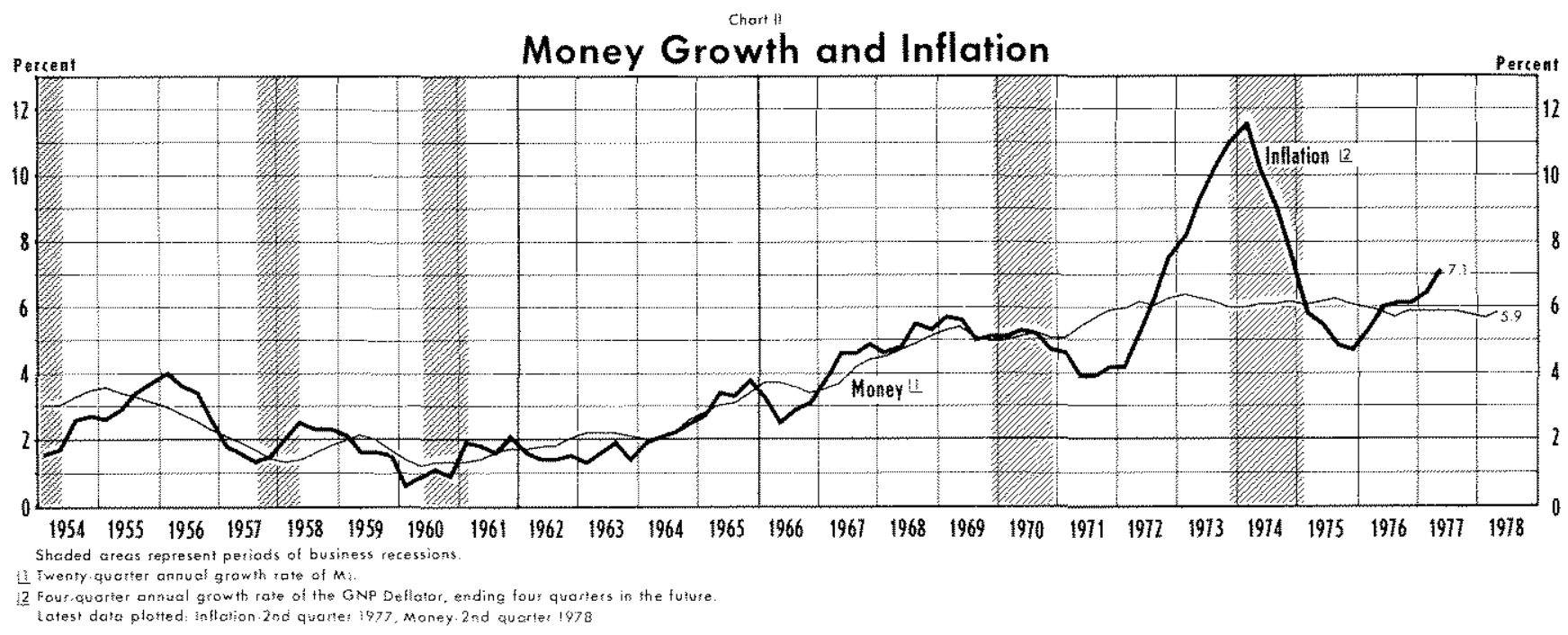

growth which prevailed in the past. One such equation, which can serve as the point of departure here, is:

$$
\Delta \ln P=\alpha_{0}+\alpha_{1} \sum_{0}^{n} w_{i} \Delta \ln M_{-i}
$$

where prices, $P$, are measured by the GNP deflator, and the money supply, $M$, is measured by M1. The rate of increase of prices and money are measured by changes in their logarithms $(\Delta \mathrm{ln}) .^{7}$ An estimate of the equation for the period I/1954-I/1978 which considers money growth in the current and prior twenty quarters is:

$$
\begin{array}{ll}
\text { (1) } & 400 \cdot \Delta \ln \mathrm{P}=-.460+1.140 \\
& \sum_{0}^{20} \mathrm{w}^{2} 400 \cdot \Delta \ln \mathrm{M}_{-i} \\
\overline{\mathrm{R}}^{2}=.64 & \mathrm{~d}=1.07 \\
\mathrm{SE}=1.54 &
\end{array}
$$

The equation has the characteristics typically hypothesized - the constant term is not significantly different

\footnotetext{
TThis equation is taken from Denis S. Kamosky, "The Link Between Money and Prices - 1971-76," this Review (June 1976), pp. 17-23. He argues that the sources of an antoregression problem indicated by the Durbon-Watson statistic for the estimate in (1') are the presence of wage and price controls and their removal in the early 1970 s as well as the price level surge associated with the large increase in the relative price of energy resources in 1973-75. Such an autoregression problem was not present up to mid-1971 and the properties of the equation were the same. It must be noted that the equation is intended as a short-hand description of the fundamental inflation process, and excludes other potentially important exogenous variables. The equation is estimated using a third degree polynominal with a zero tail constraint.
}

from zero ( $\boldsymbol{t}$-statistics are indicated in parentheses) and the sum of the past money growth coefficients is not significantly different from unity.

A simplification of this result is that the rate of inflation equals the trend rate of money stock growth. Temporary developments, such as unusually adverse weather or strikes, may temporarily influence the inflation rate from quarter to quarter, but the fundamental, permanent component of the inflation rate is determined by the trend growth of the money stock. Before examining the independent influence of slack, given this view of inflation, it is useful to look at the explanatory power of the trend rate of money stock growth for the period since 1954 (Chart II).

The errors produced with this simple relationship are most notable over the 1971-75 period. In 1971-73 the pattern of errors reflects the existence of wage and price controls and their removal. Initially the inflation rate was held below the rate indicated for money growth but later, as controls ended, the inflation rate exceeded the rate of money growth. The pattern of errors cancels out over a period long enough to allow prices to "catch up" to their normal relation to the stock of money. From late 1973 through early 1975, the relationship understates the rate of increase in prices by a sizeable amount. During this period, there was a substantial increase in the relative price of energy resources which reduced the economic capacity of the nation's productive facilities. This change caused a sharp, but brief, once-and-for-all rise in the level of prices in 1974, and 
the inflation rate quickly fell back in line with the rate indicated by past money growth.

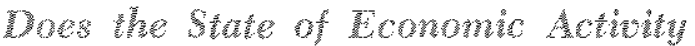

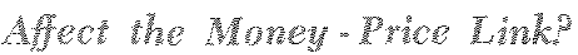

If the presence or absence of underutilized re sources has an independent influence on the rate of inflation, then the discrepancy between the inflation rate and the trend growth of the money stock should be systematically related to measures of the extent of "slack" in the economy. For example, using the cyclical view, one would expect that when there is evidence of slack in the economy, the rate of inflation would tend to be smaller than monetary growth alone would indicate. Moreover, the extent of the reduction in the inflation rate would presumably be related to the extent of resource unemployment. Conversely, when the nation's resources are fully employed, one would expect, again using the cyclical approach, that the rate of inflation would exceed the rate indicated by monetary factors alone. ${ }^{9}$

To examine this hypothesis, three measures of slack are used. The first is the "GNP gap" which measures the percent by which the economy's ability to produce goods and services, given its resources and their productivity, exceeds its actual output of goods and services as measured by real GNP. ${ }^{10} \mathrm{~A}$ given percentage gap indicates the percentage by which the nation's output of goods and services

\footnotetext{
8For a discussion of the experience in 1971-76 and the support it provides for the monetary explanation of inflation see Karnosky, "The Link Between Money and Prices." The price level impact of the capacity loss, the mechanism linking prices to the loss of economic capacity, in 1973-74 is explained in more detail in Robert $\mathbf{H}$. Rasche and John A. Tatom, "The Effects of the New Energy Regime on Economic Capacity, Production, and Prices," this Review (May 1977), pp. 2-12.
}

9This statement of the hypothesis may be considered to be a version of the new Phillips Curve view of inflation outlined above when an additional assumption is added to that view. The required assumption is that the expected rate of inflation, which shifts the Phillips Curve, is the rate indicated by the rate of monetary expansion, i.e. equation ( $\left.l^{\prime}\right)$. Then departures of the actual inflation rate from the expected itrflation rate should be systematically related to the extent of slack if the short-run Phillips Curve is neyatively sloped. Viewed in this light, the eviderce presented below is a test of the existence of a negatively sloped short-ran Plillips Curve, given the expectations assumption.

10The potential output series used here is a modiffed series based upon the methods discussed in Robert $\mathrm{H}$. Rasche and John A. Tatom, "Energy Resources and Potential GNP," this Review (June 1977), pp. 10-24. The series is prepared by this Bank and is available, together with a cescription of the method, from the author. could be expanded by fully utilizing the capital, labor, and energy resources available.

A second measure looks only at the extent of utilization of labor services. This measure is the difference between the actual unemployment rate of the civilian labor force and the rate which would prevail if labor were fully employed. ${ }^{11}$ The third measure reflects slack in the utilization of capital resources. It is calculated by subtracting the Federal Reserve Board capacity utilization rate from 87.5 percent. The latter figure is used here as full utilization of capacity, since it is the rate generally achieved at postwar cyclical peaks. Chart III shows the three measures of slack.

According to the cyclical view, the relationship between the discrepancies of the inflation rate from trend money growth in Chart II and the slack meas ures in Chart III would be expected to be signifcantly negative. In fact, the simple correlation coeffcients of the inflation rate residuals are $-.07,-.24$, and -.27 for the GNP gap, excess unemployment rate, and excess capacity measures, respectively. While the correlation coefficients all show the correct sign to support the cyclical view, they are much closer to zero (indicating no relationship) than they are to minus one (indicating perfect correlation). Moreover, regression analysis of the inflation rate discrepancy-slack relationship indicates no significant relationship between inflation and slack, once trend money growth is taken into account. The average error between the inflation rate and trend money growth is not significantly different from zero in such regressions. ${ }^{12}$

The full-employment unemployment rate used here is that prepared and described by Peter K. Clark, "Potertial GNP in the United States, 1948 1980," U.S. Productive Capacity: Estimating the Utilization Gap (Center for the Study of American Business, Washington Universify, St. Louis, 1977), pp. 21-66.

12 For example, a regression equation for the hypothesis that actual inflation during the year less trend money growth through the current guarter depends upon the current gap yields the estimated equation:

$$
\begin{gathered}
100\left(\ln \mathrm{P}_{\mathrm{t}+4}-\ln \mathrm{P}_{\mathrm{t}}\right)-20\left(\ln \mathrm{M}_{\mathrm{t}}-\ln \mathrm{M}_{\mathrm{t}}-20\right)= \\
.19-.03 \mathrm{G}_{\mathrm{t}}
\end{gathered}
$$

where $P_{t}$ is the price index in quarter $t, M_{t}$ is the stock of money in quarter $t$ and $G_{t}$ is the existing gav in period $t$. The standard error of the equation is 1.20 , and the trstatistics for the constant and $\mathrm{G}$ coefficient are 1.23 and --.66, respectively. Thus, a significant negative relationship can be rejected at the 99 percent confidence level. In addition the statistically insignificant constant indicates a zero mean difference between trend money growth and the subsequent inflation zate. The adjusted $\mathrm{R}^{2}$ is zero to two decimal places. The equations referred to in the text are estimated with a Cochrane Orcutt adjustment and in no case does the constant have a t-statistic larger than .96 , or a slack coefficient have a t-statistic larger than I.31, in absolute value. 

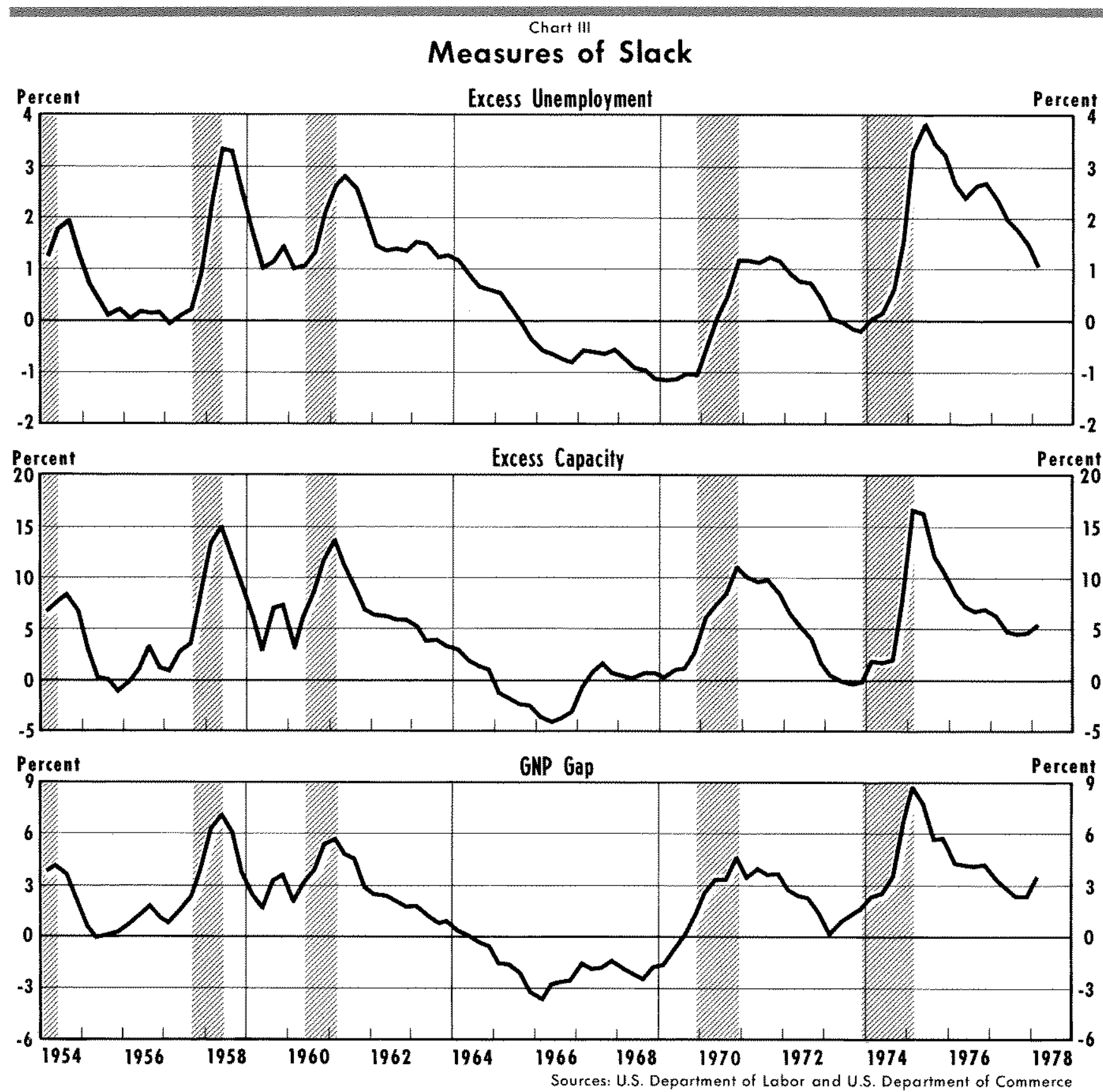

Shaded uress represen periods of busines recestions.

Lafest dato plotfed: ist quarter

A more detailed test of the hypothesis that slack influences the rate of inflation is to use equation $\left(1^{\prime}\right)$ directly. Then the cyclical view may be regarded as an argument that "initial conditions" matter or that the predetermined stage of the business cycle is a significant omitted variable in equation $(1)$ and $\left(1^{\prime}\right)$. This hypothesis can be tested by adding the lagged value of a measure of slack to equation ( $\left.1^{\prime}\right)$. Table II shows the results obtained for three alternative measures of slack: the GNP gap, the excess of the unem- ployment rate over the full-employment unemployment rate, and the Federal Reserve Board's capacity utilization rate. ${ }^{13}$ It should be noted that the capacity

13When a Cochrane-Orcutt procedure is used to adjust for the significant autoregression in the equations, none of the results are altered except that the d-statistics become satisfactory. The results reported in Table II were also obtained for the shorter sample period I/1954-II/1971. An alternative hypothesis is that slack slows inflation, but only when it is large and otherwise, inflation is determined only by money growth. Using a dummy variable of one for quarters in which 


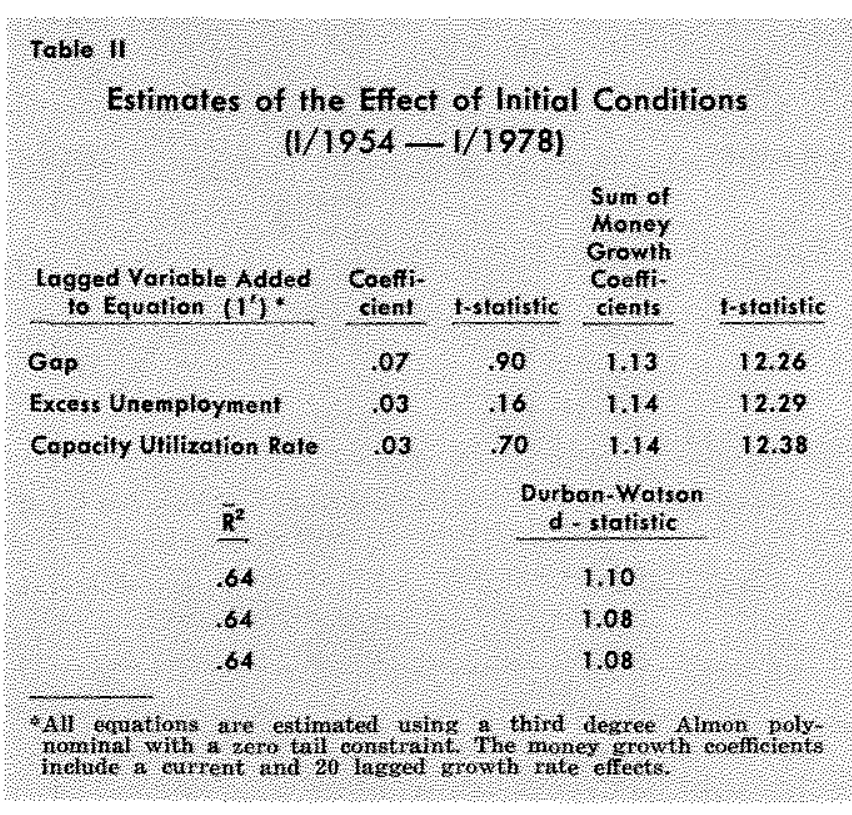

utilization rate measures the inverse of slack here since the rate is not subtracted from the arbitrary high-employment benchmark of 87.5 percent as in Chart III. The effect of initial slack on the rate of inflation has the wrong sign (positive when it is hypothesized to be negative) in the first two cases and is not significantly different from zero for any slack measure. The inclusion of a slack variable has no noticeable effect on the monetary growth coefficient or on the quality of the fit of the equation. ${ }^{14}$

The monetarist view also suggests that the extent of slack is influenced, in the short run, by changes in the rate of monetary growth, but that in the long run such changes have no effect on real economic activity. Table III presents estimates of the three slack variables as determined by the current and past money growth rates contained in the equations of Table II. ${ }^{15}$ In each case, the sum of the money growth coefficients is not significantly different from

slack is greater than one standard deviation above its sample mean, and zero otherwise again does not alter the equation ( $1^{\prime}$ ) and the dummy variable is statistically insignificant in each case.

14 Note that the d-statistic is not affected either which indicates that slack is apparently not one of the important missing variables. An alternative hypothesis might be that it is the rate at which slack is reduced, rather than the level of slack which affects the inflation rate. While it is difficult to argue that such a rate is an exogenous variable, including quarterly changes in the slack variables in the reduced form above yields the same results as for the level of slack, that is, they exert no independent influence on the inflation rate.

${ }^{2} \bar{\sigma}$ The high adjusted $R^{2}$ results from the use of a CochraneOrcutt adjustment. Without such an adjustment, the adjusted $\mathrm{R}^{2}$ is smaller than 4 for each equation, indicating that multicollinearity is not likely to be the source of the lack of significance of the slack variables in Table II. zero, verifying the hypothesized absence of long-run real effects of monetary growth. ${ }^{16}$

It is useful to examine the pattern of response of a slack variable, such as the GNP gap, to a change in the rate of money growth, since it sheds more light on the cyclical variability introduced by a change in the rate of money growth. Chart IV shows the pattern of response of the GNP gap to a one percent increase in the rate of growth of the money stock obtained from the first equation in Table III. ${ }^{17}$ For the first eight quarters of such an increase in money growth, the GNP gap is reduced until it is about .77 percentage points smaller. In the subsequent three years, however, such money growth leads to an increase in the GNP gap so that, in the long run, there has been no significant change in the size of the gap. Thus, an increase in the rate of money growth has real effects in the short run as the GNP gap is reduced. There are no long-run real effects of a permanent change in the rate of money growth; only the inflation rate is affected. ${ }^{18}$

While the analysis above shows that the stage of the business cycle does not exert an independent influence on the rate of inflation, the sometimes contrasting evidence from recession experiences may be disconcerting. The apparent conflict is easily resolved by the modern view of the Phillips Curve, which sug. gests such dynamic changes may sometimes occur, and by the monetary explanation of inflation and short-run fluctuations in economic activity. Recessions

16The results tend to support another major proposition concerning the functioning of the economy - the economy is inherently stable. Neither the gap equation nor the excess memployment equation, yield a constant tem which is significantly different from zero, indicating that while changes in the rate of money growth affect the output gap and excessive unemployment in the shom nun, both tend to zero in the long run - independently of a constant rate of money growth. Similarly, the significant constant term in the capacm ity utilization rate equation of 82 percent may be considered the steady-state capacity utilization rate which is also indevendent of axy given sustained rate of money growth. A similar conclusion using anrual data and a model of the capacity utilization rate may be found in Joln A. Tatom, "The Measurement and Meaning of Potential Output - A Comment on the Perlof and Wachter Results, CarnegieRochester Conference Series on Public Policy, Jounal of Monetary Economics, forthcoming January 1979. Not only is the natural rate the same as that derived here, the timing of the actustment of capacity utilization to changes in the money growt rate is also the same as that used here.

17The t-statistics of the individual coefficients of money growth exceed 2.9 in every quarter except at the turning point where the change in the gap is quite small in quarters 6 to 8 .

18 Similar qualitative results have recently been found by Robert J. Bamo, "Unanticipated Morey, Ontput, and the Price Level in the United States," Journal of Political Economy (Atugust 1978 ), pp. 549-80. Using a rational expectations model and anmual data, lie finds the timing of the impact of money 


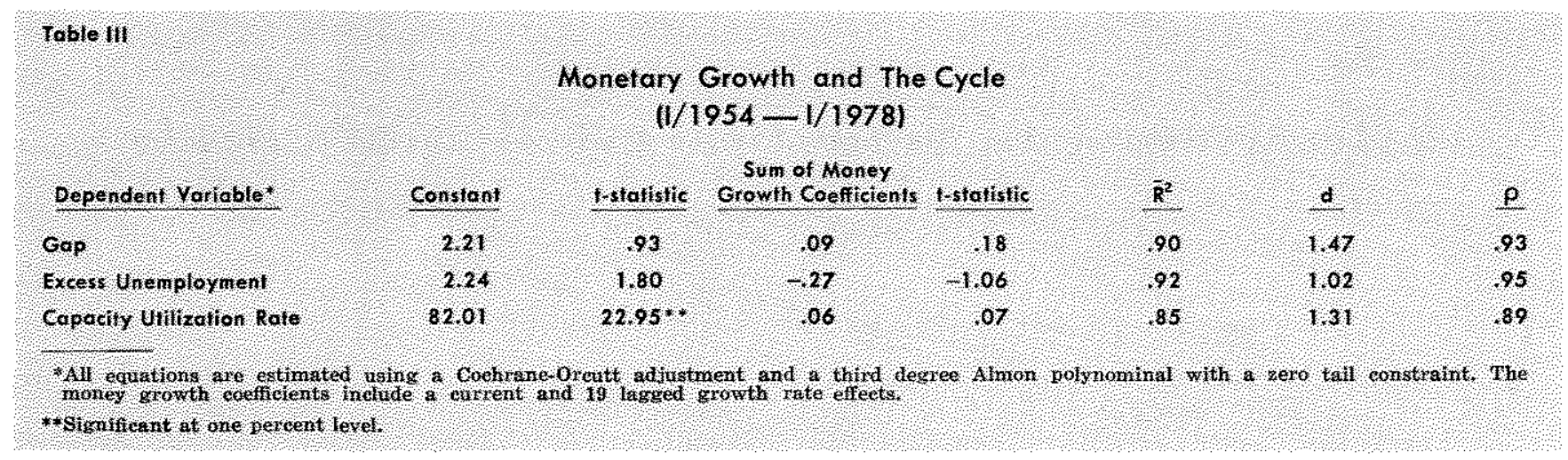

usually develop as a result of a sharp drop in the rate of growth of the stock of money. ${ }^{19}$ Since such a drop in money growth lowers the trend rate of growth of money, it is not surprising that the basic inflation rate often slows. Such a reduction in money growth slows the rate of growth of total spending for the economy's goods and services, temporarily leading to a recession. Thus, the cyclical variations in the inflation rate arise because of the influence of monetary policy on both the presence of the cycle and on the rate of inflation.

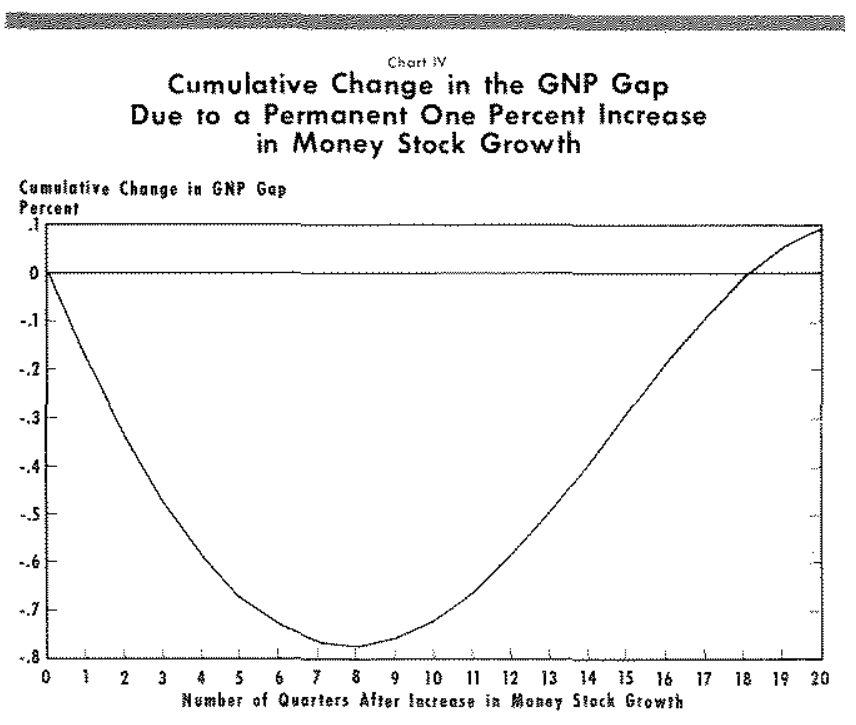

\section{CONGLUSON}

Recent concern that the inflation rate will acceler. ate in the 1978-79 period due to increasing limitations on resource avallability is unwarranted. The stage of

growth on inflation to occur over a longer period than indicated here while the temporaty effects on real output growth occur over a similar period.

19This conclusion has a considerable history. See for example, William Poole, "The Relationship of Monetary Decelerations to Business Cycle Peaks: Another Look at the Evidence," Joumal of Finance (June 1975), pp. $697-712$. the business cycle does not affect the inflation rate.20 The future course of the inflation rate will depend instead on how monetary policy affects the growth of the stock of money, Other factors, such as the impact of unusual winter weather in 1977 and 1978 or the recent coal strike, may have temporary impacts on the rate of inflation, but the inflation rate is fundamentally a monetary phenomenon. While some evidence exists which appears to provide casual support for the view that the inflation rate is influenced by the stage of the business cycle, this evidence is misleading. The confusion arises from a failure to account for both the short-run influence of monetary growth on economic activity and the long-run influence of monetary growth on the inflation rate. To the extent that the nation's cyclical experience has been caused by procyclical variations in the money stock, one would expect procyclical movements in the inflation rate. The evidence presented here provides support for this view as well as indicating the unimportance of the stage of the cycle as an independent determinant of the inflation rate.

20Phillip Cagan argues in "The Reduction of Inflation by Slack Demand, in Willam Fellne, Project Director, Contemponary Economic Problems 1978, (Washington, D. C.: American Erferprise Instifute for Public Policy Research, 1978), pp. 13-45, that slack does slow the inflation rate. He uses two different models to study the relationship between six measures of intlation and three slack measures like those used here for the periods 1953-69 and 1953-77. The alternative infation series are the GNP deflator; constmer price index; wholesale price index, crude materials; wholesale price index, intermediate materials; wholesale price index, finished goods; and average hourly eamings. Actually, the statistical evidence (t-statistics) are only supportive of the hypothesis in the cases of the consumer price index and wholesale finished goods in his first model, and to some extent, only average hourly earnings in the second model. When the experiment reported in Table $\mathbb{I}$ is performed using measures of inflation based mon other price indexes (consumer price index, all items; consumer price index for all urban consumers; producer price index, all commodities; producer price index, industrial commodities: and homrly compersation, private business sector) none of the three measmeres of sisck is significant. The data series used and sample period are not identical. Nonetheless, it appears that moe the impact of money growh on infiation is accounted for, slack does not affect the inflation rate even in the limited number of cases supported by Cagan's results. 